\title{
In Situ Diffuse Reflectance Spectroscopy of Supported Chromium Oxide Catalysts: Kinetics of the Reduction Process with Carbon Monoxide
}

\author{
Abdelhamid Bensalem,* Bert M. Weckhuysen, and Robert A. Schoonheydt \\ Centrum voor Oppervlaktechemie en Katalyse, Departement Interfasechemie, K. U. Leuven, \\ Kardinaal Mercierlaan 92, B-3001 Heverlee, Belgium
}

Received: August 14, 1996; In Final Form: November 18, $1996^{\otimes}$

\begin{abstract}
In situ diffuse reflectance spectra of supported chromium oxide catalysts are investigated for the first time at elevated temperatures under controlled reaction conditions using a specially designed diffuse reflection attachment. The obtained results are compared and discussed with those obtained by the classical diffuse reflectance spectroscopy technique. A novel method for studying the reduction kinetics of supported transition metal oxides is proposed. In the case of $\mathrm{Cr}(\mathrm{VI})$, the reduction is faster on silica than on alumina. A kinetic model is developed to explain the kinetics. It consists of the activation of $\mathrm{CO}$ by adsorption followed by the reduction of $\mathrm{Cr}^{6+}$ with formation of surface carboxylates.
\end{abstract}

\section{Introduction}

An important class of heterogeneous catalysis involves the interaction between a substrate and a redox active site, i.e. a transition metal ion (TMI). In order to study real catalytic conditions as closely as possible, in situ measurements are recommended. Up to now, measurements of the catalytic action under in situ conditions were possible with Fourier transform infrared, ${ }^{1-4}$ diffuse reflectance infrared Fourier transform, ${ }^{5-7}$ Raman, ${ }^{8-11}$ X-ray powder diffractometry, ${ }^{12}$ and extended X-ray absorption fine structure spectroscopies. ${ }^{13}$ Although diffuse reflectance spectroscopy (DRS) is ideally suited for probing the oxidation state and coordination environment of TMI and for their quantitative speciation, ${ }^{14}$ its application on supported metal oxide catalysts was not yet possible at high temperature in the presence of substrates.

Here, we present the first data of such an in situ DRS approach on supported chromium oxide catalysts. Because this type of catalyst was intensively studied in the past in our laboratory, ${ }^{15-19}$ we are able to compare the in situ DRS technique with its room temperature counterpart, and consequently, the main advantages and disadvantages of the in situ DRS measurements will be discussed. In addition, we propose in situ diffuse reflectance spectroscopy as a promising technique for the evaluation of the reduction kinetics of supported chromium oxides. To our knowledge, this method has not yet been reported.

In the literature, there are only a few papers ${ }^{20-22}$ which deal with the reduction of supported transition metal oxide catalysts in a solid-gas phase reaction using gas chromatography or mass spectrometry to measure the concentration of the consumed or the produced gas. Using temperature-programmed reduction (TPR), Finch ${ }^{22}$ studied the reduction of supported chromium oxide by $\mathrm{CO}$ and $\mathrm{H}_{2}$. While the factors such as $\mathrm{Cr}$ loading, calcination temperature, and nature of the reducing agent and the carrier influencing the determination of the kinetic parameters have been discussed by this author, the mechanism of the reduction process, the exact law describing the kinetic behavior, and the determination of the reaction order with respect to the oxide have not.

In the present work, $\mathrm{CO}$ reduction of $\mathrm{CrO}_{3}$ supported on $\mathrm{Al}_{2} \mathrm{O}_{3}$ and on $\mathrm{SiO}_{2}$ was investigated in the $400-500{ }^{\circ} \mathrm{C}$

\footnotetext{
* To whom correspondence should be addressed.

${ }^{\otimes}$ Abstract published in Advance ACS Abstracts, February 15, 1997.
}

TABLE 1: Characteristics and Sample Notations of the Supported Chromium Catalysts

\begin{tabular}{cccc}
\hline $\begin{array}{c}\text { sample } \\
\text { notation }\end{array}$ & support & support characteristics ${ }^{a}$ & $\begin{array}{c}\text { Cr loading } \\
\text { (wt \%) }\end{array}$ \\
\hline $\mathrm{Cr}-\mathrm{Al}-1$ & $\mathrm{Al}_{2} \mathrm{O}_{3}$ & $S_{0}=365 \mathrm{~m}^{2} / \mathrm{g} ; V_{\mathrm{p}}=2.0 \mathrm{~mL} / \mathrm{g}$ & 0.1 \\
$\mathrm{Cr}-\mathrm{Al}-2$ & $\mathrm{Al}_{2} \mathrm{O}_{3}$ & $S_{0}=365 \mathrm{~m}^{2} / \mathrm{g} ; V_{\mathrm{p}}=2.0 \mathrm{~mL} / \mathrm{g}$ & 0.4 \\
$\mathrm{Cr}-\mathrm{Al}-3$ & $\mathrm{Al}_{2} \mathrm{O}_{3}$ & $S_{0}=365 \mathrm{~m}^{2} / \mathrm{g} ; V_{\mathrm{p}}=2.0 \mathrm{~mL} / \mathrm{g}$ & 0.5 \\
$\mathrm{Cr}-\mathrm{Al}-4$ & $\mathrm{Al}_{2} \mathrm{O}_{3}$ & $S_{0}=365 \mathrm{~m}^{2} / \mathrm{g} ; V_{\mathrm{p}}=2.0 \mathrm{~mL} / \mathrm{g}$ & 1.2 \\
$\mathrm{Cr}-\mathrm{Si}-1$ & $\mathrm{SiO}_{2}$ & $S_{0}=735 \mathrm{~m}^{2} / \mathrm{g} ; V_{\mathrm{p}}=0.8 \mathrm{~mL} / \mathrm{g}$ & 0.5 \\
${ }^{a} S_{0}$, BET & surface area; $V_{\mathrm{p}}$, pore volume.
\end{tabular}

temperature range. This is done by quantifying the concentration of $\mathrm{Cr}^{6+}$ on alumina and silica in the presence of $\mathrm{CO}$ at a fixed temperature as a function of time. A kinetic model is proposed, and the reaction order and the rate constants are estimated.

\section{Experimental Section}

1. Sample Preparation and Characterization. The supported $\mathrm{Cr}$ catalysts were prepared by the incipient-wetness method with aqueous solutions of chromium(VI) trioxide $\left(\mathrm{CrO}_{3}\right)$ on alumina and silica supports. These supports were prepared according to procedures described elsewhere. ${ }^{12} \mathrm{Cr}$ contents were determined by ion-coupled plasma analysis. Characteristics of the catalysts and sample notations are summarized in Table 1. The impregnated samples were dried at $50{ }^{\circ} \mathrm{C}$ for $8 \mathrm{~h}$ and granulated.

2. Diffuse Reflectance Spectroscopy. In situ DR spectra were taken on a Varian Cary 5 UV-vis-NIR spectrophotometer equipped with a specially designed Praying Mantis diffuse reflection attachment (DRA) of Harrick. Its construction with two ellipsoidal mirrors provides that mainly the diffuse component of the reflected light is captured. In conjunction with the Praying Mantis DRA, a stainless steel vacuum/low-pressure reaction chamber is used with quartz windows and with three gas ports for evacuating the chamber and/or for introducing gas. The chamber can be used under static or dynamic conditions. In the last case, the gas passes through the sample. The cell temperature is controlled with an automatic temperature controller (e.g. Harrick Model ATC-30D). The sample is in the middle of a stainless steel block which contains the heating rods and the thermocouple. The measuring head of the thermocouple is situated exactly under the sample. The body of the reaction 


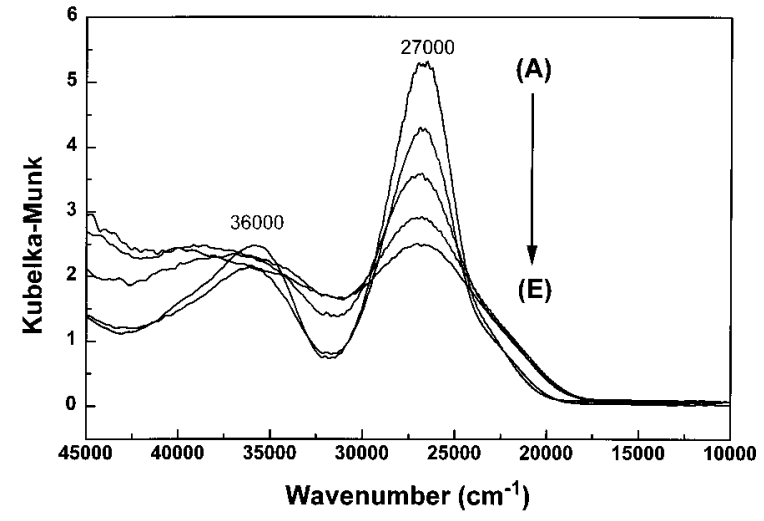

Figure 1. In situ diffuse reflectance spectra of the $\mathrm{Cr}-\mathrm{Al}-3$ catalyst taken as a function of the calcination temperature: $25^{\circ} \mathrm{C}(\mathrm{A}), 100{ }^{\circ} \mathrm{C}$ (B), $200{ }^{\circ} \mathrm{C}(\mathrm{C}), 300{ }^{\circ} \mathrm{C}(\mathrm{D})$, and $400{ }^{\circ} \mathrm{C}(\mathrm{E})$. Spectra were taken at the indicated temperatures.

chamber is cooled by circulating water. White reflectance standard $\mathrm{BaSO}_{4}$ (Kodak) was used to take a base line at $25^{\circ} \mathrm{C}$ in the Praying Mantis equipment. The thickness of the sample layer is $3 \mathrm{~mm}$, and the amount of catalyst used was around 40-65 mg. Some samples were calcined as a function of temperature in an $\mathrm{O}_{2}$ flow $(1.8 \mathrm{~L} / \mathrm{h})$ in the range $25-400{ }^{\circ} \mathrm{C}$ in order to study the influence of the heating on the in situ DRS spectra. The samples for the kinetic measurements were calcined in an $\mathrm{O}_{2}$ flow $\left(1.8 \mathrm{~L} / \mathrm{h}\right.$ ) at $500{ }^{\circ} \mathrm{C}$ (during $1 \mathrm{~h}$ ) and then evacuated under He flow $(1.8 \mathrm{~L} / \mathrm{h})$ at the applied reduction temperature (during $0.5 \mathrm{~h}$ ). The samples were then reduced in a gas stream of a mixture of $\mathrm{CO}$ and $\mathrm{He}$, containing $12.5 \% \mathrm{CO}$ $(1.8 \mathrm{~L} / \mathrm{h})$. The computer processing of the DRS spectra with a commercial software package Grams/386 (Galacties Industries Corp.) consisted of (1) conversion to wavenumbers and (2) calculation of the Kubelka-Munk (KM) function.

\section{Results}

1. In Situ Diffuse Reflectance Spectroscopy. As an example, the in situ DR spectra of the $\mathrm{Cr}-\mathrm{Al}-3$ catalyst taken at different calcination temperatures are shown in Figure 1. The spectra are characterized by two intense bands at around 27000 and $36000-41000 \mathrm{~cm}^{-1}$, which are the $\mathrm{O} \rightarrow \mathrm{Cr}^{6+}\left(\mathrm{d}^{0}\right)$ charge transfer (CT) transitions. In addition, a shoulder at $47000 \mathrm{~cm}^{-1}$ (not shown) is present which is due to the alumina support. Upon the calcination temperature being increased, the first CT band broadens and decreases in intensity. Its weak lowfrequency shoulder around $22500 \mathrm{~cm}^{-1}$, on the other hand, becomes more intense. The high-frequency band flattens out, especially toward higher wavenumbers. The increase in the intensity of the $22500 \mathrm{~cm}^{-1}$ shoulder and the flattening of the high-frequency CT band occur at $573 \mathrm{~K}$. This indicates that at that temperature $\mathrm{Cr}^{6+}$ is anchored to the support via $\mathrm{M}-\mathrm{O}-\mathrm{Cr}$ bonds $(\mathrm{M}=\mathrm{Si}, \mathrm{Al})$ as was previously concluded from conventional DR spectroscopy. ${ }^{15,16}$ Note that the observed changes in the DR spectra are not reversible with temperature because upon heating $\mathrm{H}_{2} \mathrm{O}$ is removed and $\mathrm{Cr}^{6+}$ is anchored to the surface oxygens. ${ }^{15,16}$

Figure 2 compares the in situ DRS spectra of the calcined $\mathrm{Cr}-\mathrm{Al}-3$ catalyst with its room temperature counterpart. The following observations are made: (1) all bands become broader upon heating with a significant intensity loss, (2) the 41000 $\mathrm{cm}^{-1}$ band is completely submerged in the background, and (3) there are no significant frequency shifts for the anchored species $\mathrm{Cr}^{6+}$ up to $500{ }^{\circ} \mathrm{C}$. Essentially the same results are obtained for the other catalysts. Since the intensity of the CT band $\left(27000 \mathrm{~cm}^{-1}\right)$ against the Cr loading (wt \%) is linear even

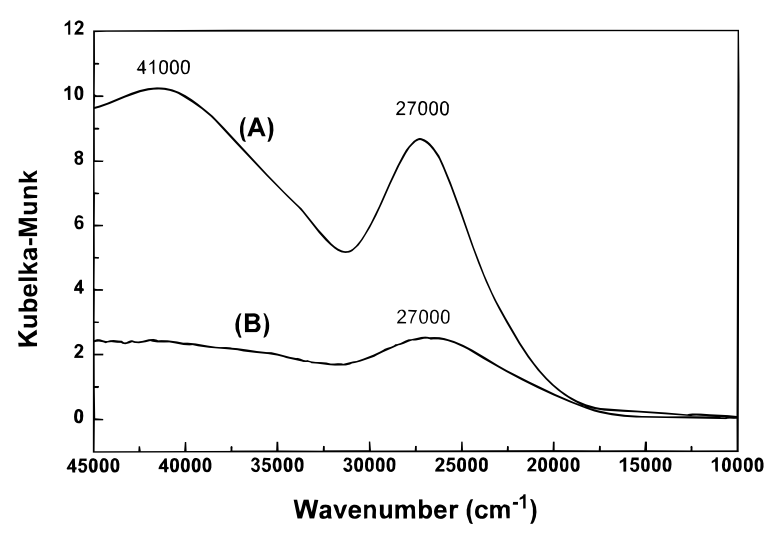

Figure 2. Comparison for the $\mathrm{Cr}-\mathrm{Al}-3$ catalyst of (A) the classical diffuse reflectance spectrum at room temperature after pretreament at $400{ }^{\circ} \mathrm{C}$ and (B) the in situ diffuse reflectance spectrum at $400{ }^{\circ} \mathrm{C}$.

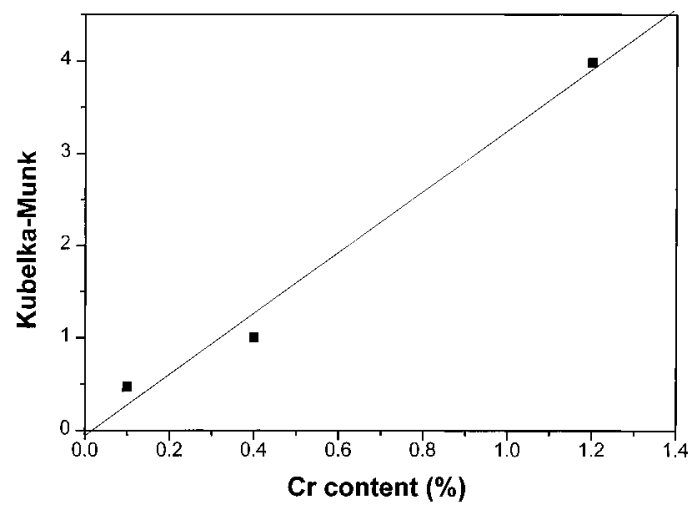

Figure 3. In situ DRS of the $\mathrm{CrO}_{3} / \mathrm{Al}_{2} \mathrm{O}_{3}$ system: influence of the $\mathrm{Cr}$ loading on the intensity of the $27000 \mathrm{~cm}^{-1}$ band at $500{ }^{\circ} \mathrm{C}$ under $\mathrm{O}_{2}$ flow.

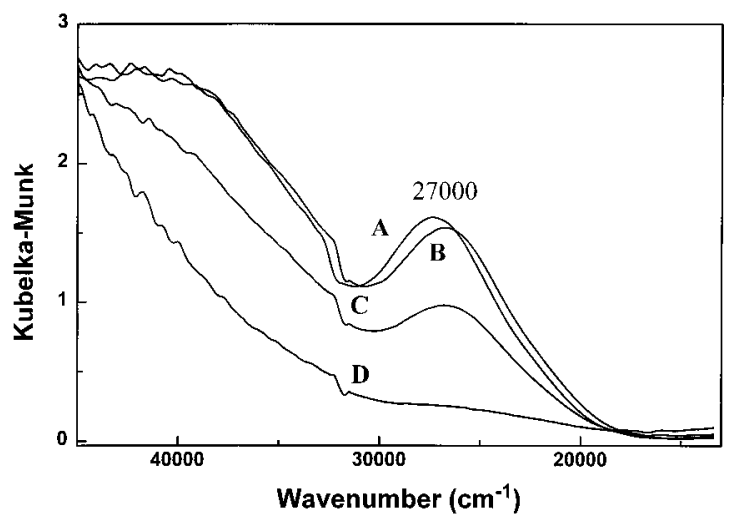

Figure 4. In situ diffuse reflectance spectra of the CO-treated $\mathrm{Cr}-$ Al-2 catalyst taken as a function of the reduction temperature (reduction time $=0.5 \mathrm{~h}): 200{ }^{\circ} \mathrm{C}(\mathrm{A}), 300^{\circ} \mathrm{C}(\mathrm{B}), 400{ }^{\circ} \mathrm{C}(\mathrm{C})$ and $500{ }^{\circ} \mathrm{C}(\mathrm{D})$.

at high temperature (see Figure 3), in situ DR spectroscopy can be used to evaluate the reduction process with $\mathrm{CO}$ as a function of temperature. This is shown in Figure 4 for the $\mathrm{Cr}-\mathrm{Al}-2$ catalyst. Both CT bands of $\mathrm{Cr}^{6+}$ gradually decrease upon increasing the reduction temperature and are totally absent after reduction at $500{ }^{\circ} \mathrm{C}$. A weak residual band around $25000 \mathrm{~cm}^{-1}$ and the intensity increase around $15000 \mathrm{~cm}^{-1}$ are indicative for $\mathrm{Cr}^{3+}$.

2. Spectroscopic Method for Measuring Reduction Kinetics. 2.1. Theory. The overall reduction reaction can be represented as

$$
\mathrm{Cr}_{\mathrm{a}}+n \mathrm{CO} \leftrightarrow \mathrm{Cr}_{\mathrm{r}}+n \mathrm{CO}_{2}
$$

where $\mathrm{Cr}_{\mathrm{a}}$ stands for anchored $\mathrm{Cr}^{6+}$ and $\mathrm{Cr}_{\mathrm{r}}$ for reduced $\mathrm{Cr} . \mathrm{Cr}_{\mathrm{a}}$ 


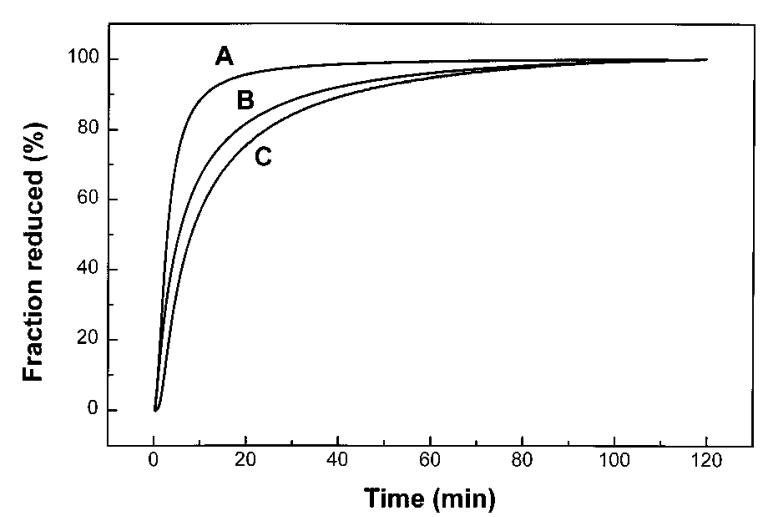

Figure 5. The fraction reduced as revealed by DRS in function of $\mathrm{Cr}$ loading: (A) $\mathrm{Cr}-\mathrm{Al}-4$, (B) $\mathrm{Cr}-\mathrm{Al}-2$, and (C) $\mathrm{Cr}-\mathrm{Al}-1$.

can be chromate-like or dichromate-like. The former is predominant on alumina, the latter on silica at the loading of the present investigation. ${ }^{15,16,18} \mathrm{Cr}_{\mathrm{r}}$ is $\mathrm{Cr}^{3+}$ on alumina and a $\mathrm{Cr}^{3+}, \mathrm{Cr}^{2+}$ mixture on silica.

The corresponding rate equation is

$$
\frac{\mathrm{d}\left[\mathrm{Cr}_{\mathrm{a}}\right]}{\mathrm{d} t}=k\left[\mathrm{Cr}_{\mathrm{a}}\right]^{\alpha}[\mathrm{CO}]^{\beta}
$$

which at constant partial pressure of $\mathrm{CO}$ becomes

$$
\frac{\mathrm{d}\left[\mathrm{Cr}_{\mathrm{a}}\right]}{\mathrm{d} t}=k^{\prime}\left[\mathrm{Cr}_{\mathrm{a}}\right]^{\alpha}
$$

Equation 3 can be used to determine the kinetic parameters of the reduction if $\left[\mathrm{Cr}_{\mathrm{a}}\right]$ can be followed as a function of time at constant temperature. The CT band around $27000 \mathrm{~cm}^{-1}$ can be used for that purpose, as its intensity varies linearly with the amount of $\mathrm{Cr}$ in the range of loading envisaged (Figure 3). This means that the Kubelka-Munk function is proportional to the loading of $\mathrm{Cr}^{6+}$ :

$$
F\left(R_{\infty}\right)=\left(1-R_{\infty}\right)^{2} / 2 R_{\infty}=(K / S) \propto\left[\mathrm{Cr}_{\mathrm{a}}\right]
$$

In other words, the conditions of the validity of the KM function are fulfilled, and the apparent scattering coefficient $S$ is constant. Other conditions are (1) CO gas must flow through the sample and (2) the diffusion limitations must be avoided. First, we carried out a preliminary study to find the optimal working conditions.

2.2. Experimental Conditions. The Praying Mantis reaction chamber can be considered as a fixed bed integral microreactor. The partial pressure of $\mathrm{CO}$ in the catalyst bed must be constant. Thus flow rates should not influence the kinetics, and this was verified in the present study for flow rates in the range 10-60 $\mathrm{mL} / \mathrm{min}$.

The Cr content affects the rate of reduction but not the shape of the kinetic curves. This result was deduced from experiments carried out on $\mathrm{CrO}_{3} / \mathrm{Al}_{2} \mathrm{O}_{3}$ samples with $0.1,0.4$, and 1.2 wt $\%$ Cr (Figure 5).

The thickness of the catalyst bed does influence the $\mathrm{Cr}_{\mathrm{a}}$ intensity profile as a function of reduction time, in that complete reflectance of the nonabsorbed light must be assured. We found that for thicknesses of 2 and $3 \mathrm{~mm}$ the reduction curves are the same but that for a $1 \mathrm{~mm}$ thickness deviations occur.

In conclusion, the following working conditions were optimal: thickness of the catalyst bed, $3 \mathrm{~mm}$; grain size, $0.4-0.5$ $\mathrm{mm}$; flow rate, $30 \mathrm{~mL} / \mathrm{min}$.

2.3. Results. Figure 6 shows examples of $\mathrm{Cr}_{\mathrm{a}}$ intensities versus time profiles of the $\mathrm{Cr}-\mathrm{Al}-2$ and $\mathrm{Cr}-\mathrm{Si}-1$ catalysts at
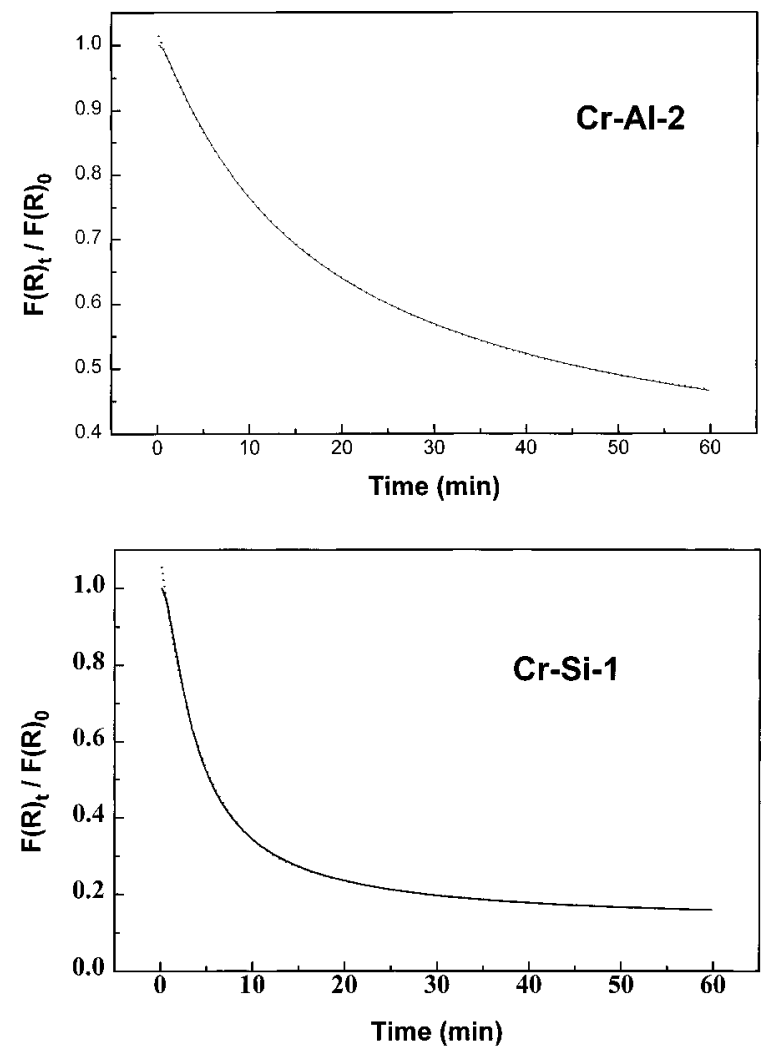

Figure 6. Kinetic curves of $\mathrm{CO}$ reduction of the $\mathrm{Cr}-\mathrm{Al}-2$ and $\mathrm{Cr}-$ Si-1 catalysts at $450{ }^{\circ} \mathrm{C}$ : solid line, experimental data and dotted line, bifunction exponential fit.

$450{ }^{\circ} \mathrm{C}$. Similar plots are obtained at other reduction temperatures and $\mathrm{Cr}$ loadings. Figure 6 shows that (1) the $\mathrm{Cr}_{\mathrm{a}}$ intensity decreases exponentially with reduction time, indicating firstorder kinetics, and (2) the reduction is faster on silica than on alumina. The intensity-time profiles can be simulated by a sum of two exponentials, i.e. $y(t)=A_{1} \mathrm{e}^{-t / x_{1}}+A_{2} \mathrm{e}^{-t / x_{2}}$ (Figure $6)$.

3. Kinetic Model. Supported Cr catalysts are by definition heteregeneous systems. Chromate- and dichromate-like species are anchored at the surface, and a variety of anchoring sites may be envisaged on the surface of amorphus oxides such as silica and alumina. The CT band at $27000 \mathrm{~cm}^{-1}$, used to follow the reduction kinetics, contains contributions of all the possible $\mathrm{Cr}_{\mathrm{a}}$ species. Therefore, only an overall reduction scheme can be proposed with the oxidation state $m<6$ :

$$
\begin{aligned}
\mathrm{Cr}_{\mathrm{a}}+\mathrm{CO} \underset{k_{-1}}{\stackrel{k_{1}}{\rightleftarrows}} \mathrm{Cr}_{\mathrm{a}}(\mathrm{CO})_{\mathrm{ads}} \stackrel{k_{2}}{\longrightarrow} \mathrm{Cr}^{m+}\left(\mathrm{CO}_{2}\right)_{\mathrm{ads}} \underset{k_{-3}}{\stackrel{k_{3}}{\rightleftarrows}} \\
\mathrm{Cr}^{m+}+\mathrm{CO}_{2}(m<6)
\end{aligned}
$$

The first step is the adsorption of $\mathrm{CO}$ on $\mathrm{Cr}_{\mathrm{a}}$; the second one is the reduction, whereby $\mathrm{CO}_{2}$ remains adsorbed as a carboxylate species. This carboxylate complex then decomposes into $\mathrm{CO}_{2}$ and a $\mathrm{Cr}^{m+}$ species on the surface. This idea of intermediate surface carboxylates was also proposed for the reduction of bulk metal oxides such as $\mathrm{TiO}_{2}, \mathrm{SnO}_{2}$, and $\mathrm{ZnO}$. ${ }^{23}$

The experimental evidence for a two-exponential decay of $\mathrm{Cr}_{\mathrm{a}}$ suggests that intermediate $\mathrm{Cr}_{\mathrm{a}}(\mathrm{CO})_{\mathrm{ads}}$ is neither in steady state nor in equilibrium with the reactants. It is preferable then to obtain the exact solutions of the rate equations. In addition, by using exact solutions we can calculate three rate constants instead of only one when using the steady state and equilibrium approximations (leading to mono-exponential decay). 


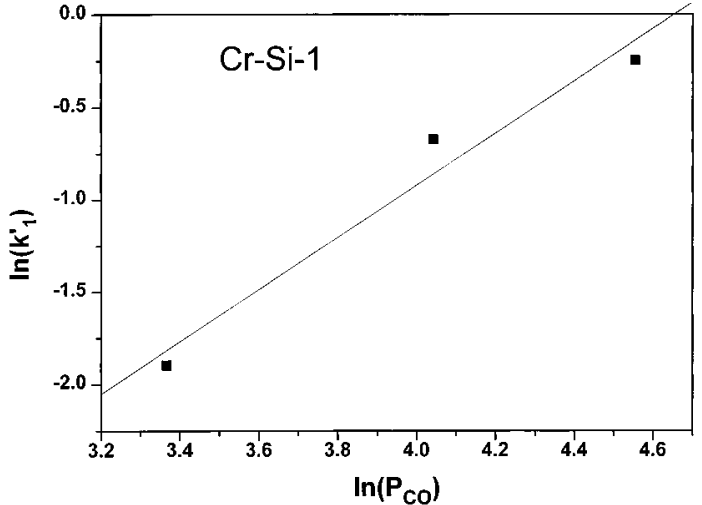

Figure 7. Double-logarithmic plot of the pseudo-first-order rate constant against $\mathrm{CO}$ partial pressure of the $\mathrm{Cr}-\mathrm{Si}-1$ catalyst.

Using scheme I, one can write

$$
\frac{\mathrm{d}\left[\mathrm{Cr}_{\mathrm{a}}\right]}{\mathrm{d} t}=k_{-1}\left[\mathrm{Cr}_{\mathrm{a}}(\mathrm{CO})_{\mathrm{ads}}\right]-k_{1}^{\prime}\left[\mathrm{Cr}_{\mathrm{a}}\right]
$$

and

$$
\begin{array}{r}
\frac{\mathrm{d}\left[\mathrm{Cr}_{\mathrm{a}}(\mathrm{CO})_{\mathrm{ads}}\right]}{\mathrm{d} t}=k_{1}^{\prime}\left[\mathrm{Cr}_{\mathrm{a}}\right]-k_{-1}\left[\mathrm{Cr}_{\mathrm{a}}(\mathrm{CO})_{\mathrm{ads}}\right]- \\
k_{2}\left[\mathrm{Cr}_{\mathrm{a}}(\mathrm{CO})_{\mathrm{ads}}\right]
\end{array}
$$

where $k_{1}{ }^{\prime}$ is the pseudo-first-order rate constant (defined as $k_{1}^{\prime}$ $\left.=k_{1}[\mathrm{CO}]^{\beta}\right)$. The following exact kinetic law describing the reduction of $\mathrm{Cr}_{\mathrm{a}}$ can be calculated using the chemical matrix formulation $^{24,25}$

$$
\begin{aligned}
{\left[\mathrm{Cr}_{\mathrm{a}}\right]=\left[C_{0} /\left(\lambda_{1}-\lambda_{2}\right)\right]\left[\left(k_{-1}+k_{2}-\right.\right.} & \left.\lambda_{2}\right) \mathrm{e}^{-\lambda_{2} t}- \\
& \left.\left(k_{-1}+k_{2}-\lambda_{1}\right) \mathrm{e}^{-\lambda_{1} t}\right]
\end{aligned}
$$

where $\lambda_{1}$ and $\lambda_{2}$ are defined as $\lambda_{1}=1 / 2_{2}(p+q)$ and $\lambda_{2}=1 / 2(p$ $-q)$ with $p=k_{1}^{\prime}+k_{-1}+k_{2}, q=\left(p^{2}-4 k_{1}^{\prime} k_{2}\right)^{1 / 2}$, and $C_{0}=$ $\left(F\left(R_{\infty}\right)_{t=0}-F\left(R_{\infty}\right)_{t=\infty}\right) / K ; C_{0}$ is the initial concentration.

4. Determination of Rate Constants and Reaction Orders. Equation 7 is a sum of two exponentials. Thus, we can write

$$
\begin{aligned}
A_{1} \mathrm{e}^{-t / x_{1}}+A_{2} \mathrm{e}^{-t / x_{2}}=\left[\left(F\left(R_{\infty}\right)_{\mathrm{t}=0}-F\left(R_{\infty}\right)_{\mathrm{t}=\infty}\right) / K\left(\lambda_{1}-\lambda_{2}\right)\right] \times \\
{\left[\left(k_{-1}+k_{2}-\lambda_{2}\right) \mathrm{e}^{-\lambda_{2} t}-\left(k_{-1}+k_{2}-\lambda_{1}\right) \mathrm{e}^{-\lambda_{1} t}\right] }
\end{aligned}
$$

from which it follows that

$$
\begin{gathered}
k_{1}^{\prime}=1 / x_{2}-\left[A_{1}\left(1 / x_{2}-1 / x_{1}\right) /\left(A_{1}+A_{2}\right)\right] \\
k_{2}=\left[\left(1 / x_{2}\right)\left(1 / x_{1}\right)\right]^{2} / k_{1}^{\prime} \\
k_{-1}=\left(1 / x_{2}\right)+\left(1 / x_{1}\right)-k_{2}-k_{1}^{\prime}
\end{gathered}
$$

and indirectly $k_{1}=k_{1}^{\prime} /[\mathrm{CO}]$ if we assume that the reaction order with respect to $\mathrm{CO}, \beta$, equals 1 . We have tried to determine the order in $\mathrm{CO}$ by measuring the reduction kinetics for three partial pressures of $\mathrm{CO}$ at $500{ }^{\circ} \mathrm{C}$. The double logarithmic plot of Figure 7 does give an order of $1.4 \pm 0.60$, and we consider 1 to be a reasonable number. The values of $A_{1}, A_{2}, x_{1}$, and $x_{2}$ for $\mathrm{Cr}-\mathrm{Al}-2$ and $\mathrm{Cr}-\mathrm{Si}-1$ are reported in Tables 2 and 3, respectively, and the calculated rate constants are summarized in Tables 4 and 5. One can deduce from Tables 4 and 5 that (1) $\mathrm{CO}$ reduction on $\mathrm{CrO}_{3} / \mathrm{SiO}_{2}$ catalysts is much faster than that on $\mathrm{CrO}_{3} / \mathrm{Al}_{2} \mathrm{O}_{3}$ catalysts and (2) the rate constant $k_{2}$ is at least 100 times smaller than the other rate constants, which
TABLE 2: Calculated Fitting Parameters for the $\mathrm{Cr}-\mathrm{Al}-2$ Catalyst

\begin{tabular}{ccccc}
\hline$T\left({ }^{\circ} \mathrm{C}\right)$ & $x_{1}\left(\mathrm{~min}^{-1}\right)$ & $x_{2}\left(\mathrm{~min}^{-1}\right)$ & $A_{1}$ & $A_{2}$ \\
\hline 400 & 14.06 & 74.77 & 119.7 & 194.0 \\
425 & 37.94 & 8.668 & 43.67 & 26.38 \\
450 & 33.37 & 8.832 & 42.62 & 24.70 \\
475 & 6.09 & 33.16 & 45.23 & 33.28 \\
500 & 4.455 & 25.77 & 39.50 & 23.00
\end{tabular}

TABLE 3: Calculated Fitting Parameters for the $\mathrm{Cr}-\mathrm{Si}-1$ Catalyst

\begin{tabular}{ccccc}
\hline$T\left({ }^{\circ} \mathrm{C}\right)$ & $x_{1}\left(\mathrm{~min}^{-1}\right)$ & $x_{2}\left(\mathrm{~min}^{-1}\right)$ & $A_{1}$ & $A_{2}$ \\
\hline 400 & 5.84 & 24.22 & 544.8 & 411.8 \\
425 & 3.85 & 17.55 & 358.6 & 293.6 \\
450 & 4.07 & 19.95 & 311.8 & 97.41 \\
475 & 2.43 & 11.57 & 112.0 & 48.07 \\
500 & 1.21 & 7.625 & 1368 & 99.66
\end{tabular}

TABLE 4: Calculated Rate Constants of the $\mathbf{C r}-\mathrm{Al}-2$ Catalyst

\begin{tabular}{ccccc}
\hline & \multicolumn{4}{c}{ calculated rate constants } \\
\cline { 2 - 5 }$T\left({ }^{\circ} \mathrm{C}\right)$ & \multicolumn{1}{c}{$\begin{array}{c}10^{+2} k_{1}^{\prime} \\
\left(\mathrm{min}^{-1}\right)\end{array}$} & $\begin{array}{c}10^{+2} k_{-1} \\
\left(\mathrm{~min}^{-1}\right)\end{array}$ & $\begin{array}{c}10^{+5} k_{2} \\
\left(\mathrm{~min}^{-1}\right)\end{array}$ & $\begin{array}{c}10^{+2} k_{1}^{\prime} \\
\left(\mathrm{min}^{-1} \mathrm{~mol}^{-1} \mathrm{~g}\right)\end{array}$ \\
\hline 400 & $3.5 \pm 0.7$ & $4.8 \pm 0.9$ & $2.4 \pm 0.4$ & $15.1 \pm 3.0$ \\
425 & $5.9 \pm 1.0$ & $8.1 \pm 1.6$ & $15.4 \pm 3.0$ & $24.0 \pm 4.8$ \\
450 & $6.0 \pm 1.2$ & $8.2 \pm 1.6$ & $19.0 \pm 3.8$ & $26.4 \pm 5.2$ \\
475 & $10.3 \pm 2.6$ & $8.7 \pm 1.5$ & $30.0 \pm 6.0$ & $50.5 \pm 10.0$ \\
500 & $15.5 \pm 3.1$ & $10.5 \pm 2.1$ & $47.7 \pm 9.5$ & $66.8 \pm 13.3$
\end{tabular}

TABLE 5: Calculated Rate Constants Of The $\mathrm{Cr}-\mathrm{Si}-1$ Catalyst

\begin{tabular}{ccccc}
\hline \multicolumn{4}{c}{ calculated rate constants } \\
\cline { 2 - 5 }$T\left({ }^{\circ} \mathrm{C}\right)$ & $\begin{array}{c}10^{+2} k_{1}^{\prime} \\
\left(\mathrm{min}^{-1}\right)\end{array}$ & \multicolumn{1}{c}{$\begin{array}{c}10^{+2} k_{-1} \\
\left(\mathrm{~min}^{-1}\right)\end{array}$} & $\begin{array}{c}10^{+5} k_{2} \\
\left(\mathrm{~min}^{-1}\right)\end{array}$ & $\begin{array}{c}10^{+2} k_{1} \\
\left(\mathrm{~min}^{-1} \mathrm{~mol}^{-1} \mathrm{~g}\right)\end{array}$ \\
\hline 400 & $11.5 \pm 2.3$ & $6.0 \pm 1.2$ & $43.2 \pm 8.6$ & $44.0 \pm 8.8$ \\
425 & $16.8 \pm 3.3$ & $14.6 \pm 2.9$ & $129.7 \pm 25.9$ & $64.2 \pm 12.8$ \\
450 & $19.9 \pm 3.9$ & $9.5 \pm 1.9$ & $76.0 \pm 15.2$ & $78.6 \pm 15.7$ \\
475 & $31.3 \pm 6.2$ & $35.9 \pm 7.1$ & $401.8 \pm 80.3$ & $128.2 \pm 25.6$ \\
500 & $73.1 \pm 14.6$ & $13.9 \pm 2.7$ & $1105.9 \pm 221.1$ & $309.2 \pm 61.8$
\end{tabular}

means that the first-order irreversible reaction is the slowest step and consequently rate determining.

When an Arrhenius plot is made of the $k_{2}$ values of Tables 3 and 4 (Figure 8), the scattering of the data points prohibits the obtainment of physically meaningful activation energies. There is some indication that the high-temperature slope is different from the low-temperature slopes, both for $\mathrm{Al}_{2} \mathrm{O}_{3}$ and $\mathrm{SiO}_{2}$, but looking for interpretation would be too speculative.

\section{Discussion}

Heterogeneous catalysts usually act above room temperature in a catalytic reaction after a suitable activation treatment. The fundamental understanding of the heterogeneous catalysis requires knowledge of the nature and amount of the active sites. This knowledge is usually obtained from spectroscopic measurements at room temperature or below, often in conditions far from real activation or catalysis conditions. It is not straightforward to extrapolate the spectroscopic results to real catalytic conditions. There is therefore a need to perform spectroscopic measurements in conditions as close as possible to activation and catalytic conditions. In the present paper this has been attempted with the DRS technique and the reduction of supported $\mathrm{Cr}$ catalysts, a common activation procedure of these catalysts.

1. Evaluation of in Situ DRS Spectroscopy. As expected, a high-temperature DRS spectrum contains bands which are considerably broadened when recorded at high temperature. If 


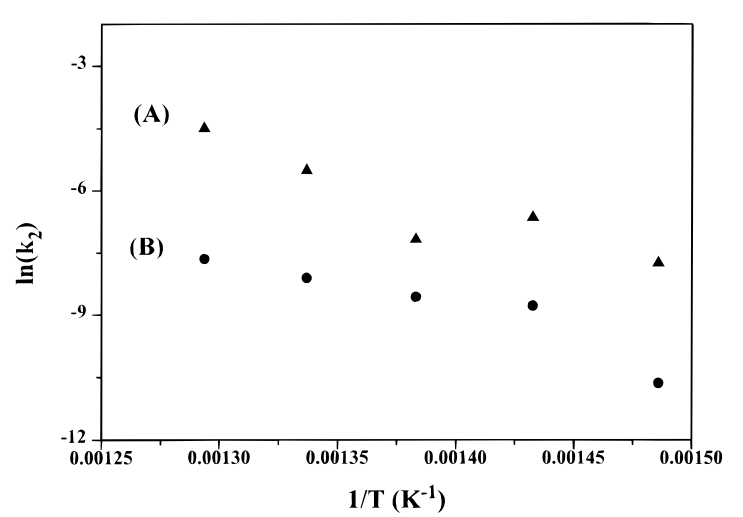

Figure 8. Arrhenius plots of $\mathrm{Cr}-\mathrm{Si}-1$ (A) and $\mathrm{Cr}-\mathrm{Al}-2$ (B) catalysts.

the bands are characterized by a high molar extinction coefficient (are intense), such as charge transfer bands in general and the $\mathrm{O} \rightarrow \mathrm{Cr}^{6+}$ charge transfer in particular, then even at high temperature a linear relation results between the band intensity and the $\mathrm{Cr}$ content, similar to what was obtained from room temperature spectra. ${ }^{15}$ The $27000 \mathrm{~cm}^{-1}$ band of chromate is such a band. The second $\mathrm{O} \rightarrow \mathrm{Cr}^{6+}$ charge transfer band around $40000 \mathrm{~cm}^{-1}$ is (1) broader and (2) superposed on the background spectrum of the support. As a consequence, its hightemperature profile becomes almost undetectable. It cannot be used for quantitative purposes. This was also the case for the room temperature spectra. ${ }^{15}$

As an extention of these observations, one can propose that $\mathrm{d}-\mathrm{d}$ transitions of transition metal ions will be difficult to measure at high temperature because they are inherently weak (mostly symmetry forbidden) and broad. Only in the case of allowed $\mathrm{d}-\mathrm{d}$ transitions, and therefore strong bands, may one attempt to do quantitative high-temperature DRS. This is the case for pseudo-tetrahedral complexes.

Finally, our results also indicate that the conditions for application of the Kubelka-Munk theory remain valid in the temperature range investigated. When a chemical reaction such as the reduction of $\mathrm{Cr}^{6+}$ has to be studied in situ spectroscopically, supplementary conditions have to be fulfilled. The light beam probes some thickness of catalyst bed. This thickness depends on the particle size and shape, the particle density, and the amount of light absorbed. During a reaction, such as the reduction of $\mathrm{Cr}^{6+}$ to $\mathrm{Cr}^{3+} / \mathrm{Cr}^{2+}$, in which the $27000 \mathrm{~cm}^{-1}$ decreases in intensity with time, the probed sample thickness will slightly change with time. In any case, one must assure that (1) the reactant concentration ( $\mathrm{CO}$ in our case) is constant over the probed bed thickness and (2) the reaction is homogeneously spread over the probed bed. The optimum experimental conditions have been determined in this paper for the reduction of $\mathrm{Cr}^{6+}$ with $\mathrm{CO}$. They will have to be determined for every catalyst-reaction combination experimentally.

2. Kinetics of the Reduction of Supported Chromium Catalysts. In kinetic studies one usually follows the concentration of a reagent or a product with time. With the present in situ DRS method the transition metal ion is probed directly. It is therefore complementary to conventional kinetic techniques.

The surface of silica and alumina is by definition heterogeneous. Thus, after activation the anchored (di)chromate species have slightly different chemical environments. This is wellknown and gives chromate bands which are broader than those in solution. This phenomenon is called inhomogeneous line broadening. When one then follows the intensity decrease of the $\mathrm{O} \rightarrow \mathrm{Cr}^{6+} \mathrm{CT}$ band at $27000 \mathrm{~cm}^{-1}$, one obtains "average" kinetics of the heterogeneous samples.

The first step in reduction is the activation of the reducing agent. ${ }^{26}$ According to our model the first step of the reduction is the adsorption of CO on the surface at some unspecified site, resulting from in its activation. The second step, the actual reduction of $\mathrm{Cr}^{6+}$, is rate determining and occurs with formation of surface carboxylates, which decompose to $\mathrm{CO}_{2}$. The oxygen comes from the chromate or di(poly)chromate species. Thus, the reduction of $\mathrm{Cr}^{6+}$ is accompanied by a decrease in the number of oxygens in its coordination sphere, thus leaving empty coordination sites, which can be used for specific adsorption and catalysis. This mechanism invokes a reaction between anchored "chromate" and adsorbed CO. It can therefore be classified as a stepwise mechanism with alternating reduction of the surface and oxidation of the reagent, in which the rate is proportional to the surface coverage of both chromate and CO. The former is constant, and the latter is proportional to the partial pressure of $\mathrm{CO}$ (as in unimolecular decomposition following Langmuir law). In that way, the first-order dependence on $\mathrm{CO}$ pressure is explained.

The overall reaction order is 2 , but taking into account the experimental uncertainties, it is safer to state between 2 and 3 . This is exactly what was found by Finch on the basis of TPR study. ${ }^{22}$ No explanation was offered at that time. Our model is, as explained, to be considered as an averaged model, which explains the kinetics of the $\mathrm{Cr}^{6+}$ reduction in general terms, without taking into account the heterogeneous nature of the surfaces, the presence of different $\mathrm{Cr}^{6+}$ species, and the fact that the degreee of reduction may be different for silica and alumina.

In any case, the rate constants of the rate-determining step clearly indicate that reduction of $\mathrm{Cr}^{6+}$ on silica is faster than on alumina. Several reasons can be put forward to explain this behavior: (1) whereas there is only chromate on alumina, silica contains chromate and dichromate ${ }^{15,18}$ (2) the $\mathrm{Cr}^{6+}-$ - -O (Al) bond is stronger than the $\mathrm{Cr}^{6+}-\mathrm{-}_{-} \mathrm{O}(\mathrm{Si})$ bond; (3) alumina stabilizes intermediate oxidation states such as $\mathrm{Cr}^{5+}$ and $\mathrm{Cr}^{3+}$; and (4) these $\mathrm{Cr}^{5+}, \mathrm{Cr}^{3+}$ species might migrate into the bulk of alumina, where their reduction is much more difficult.

\section{Conclusions}

The technique of in situ DRS has been proposed to study the reduction kinetics of supported chromium catalysts. Its advantage is that the TMI is probed directly. Therefore, the technique is complementary to more conventional methods. The experimental conditions must be chosen carefully, and we anticipate also that, due to band intensities, not all supported TMI can be studied.

The reduction of supported $\mathrm{Cr}^{6+}$ is faster on silica than on alumina. In both cases the overall order is stated between 2 and 3. A model to explain the kinetics is a two-step mechanism: the adsorption of $\mathrm{CO}$ to activate it and the reduction, which is rate-determining. On the basis of this model we anticipate (1) the presence of adsorbed $\mathrm{CO}$ and (2) carboxylates and possibly carbonates on the surface. In situ FTIR studies are in progress to verify these hypotheses and the proposed mechanism.

Acknowledgment. A.B. and B.M.W. acknowledge a grant from the K. U. Leuven as a postdoctoral research fellow and the research grant from the National Fund for Scientific Research (NFWO) of Belgium, respectively. This work was financially supported by the Geconcerteerde Onderzoeksactie (GOA) of the Flemish Government and by the Fonds voor Kollectief Fundamenteel Onderzoek (FKFO) under Grant No. 2.0050.93.

\section{References and Notes}

(1) Aylor, A. W.; Larsen, S. C.; Reimer, J. A.; Bell, A. T. J. Catal. 1995, 157, 592 . 
(2) Meijers, S.; Ponec, V. J. Catal. 1996, 160, 1.

(3) Balakos, M. W.; Chuang, S. S. C.; Srinivas, G.; Brundage, M. A. J. Catal. 1995, 157, 51.

(4) Meijers, S.; Gielgens, L. H.; Ponec, V. J. Catal. 1995, 156, 147.

(5) Hamadeh, I. M.; King, D.; Griffiths, P. R. J. Catal. 1984, 88, 264.

(6) Chalmers, J. M.; Mckenzie, M. W.; Willis, H. A. Appl. Spectrosc. 1984, 38, 786 .

(7) Yang, P. W.; Casal, H. L. J. Phys. Chem. 1986, 90, 2422.

(8) Niemantsverdriet, J. W. Spectroscopy in Catalysis; VCH Publishers: New York, 1993

(9) Banares, M. A.; Hu, H.; Wachs, I. E. J. Catal. 1994, 150, 407.

(10) Hu, H.; Wachs, I. E. J. Phys. Chem. 1995, 99, 10922.

(11) Weckhuysen, B. M.; Wachs, I. E. J. Phys. Chem., in press.

(12) Thomas, J. M.; Williams, C.; Rayment, T. J. Chem. Soc., Faraday Trans. 1 1988, 84, 2915.

(13) Dooryhee, E.; Catlow, C. R. A.; Couves, J. W.; Maddox, P. J.; Thomas, J. M.; Greaves, G. N.; Steel, A. T.; Townsend, R. P. J. Phys. Chem. 1991, 95, 4514.

(14) Schoonheydt, R. A. In Characterization of Heterogeneous Catalysts, Delannay, F., Ed.; Marcel Dekker, Inc.: New York, 1984; Chapter 4.

(15) Weckhuysen, B. M.; De Ridder, L. M.; Schoonheydt, R. A. J. Phys. Chem. 1993, 97, 4756.
(16) Weckhuysen, B. M.; Verberckmoes, A. A.; Buttiens, A. L.; Schoonheydt, R. A. J. Phys. Chem. 1994, $98,579$.

(17) Weckhuysen, B. M.; Spooren, H. J.; Schoonheydt, R. A. Zeolites 1994, 14, 450.

(18) Weckhuysen, B. M.; Schoonheydt, R. A.; Jehng, J. M.; Wachs, I. E.; Cho, S. J.; Ryoo, R.; Kijlstra, S.; Poels, E. J. Chem. Soc., Faraday Trans. 1995, 91, 3245.

(19) Weckhuysen, B. M.; Wachs, I. E.; Schoonheydt, R. A. Stud. Surf. Sci. Catal. 1995, 91, 151.

(20) Hurst, N. W.; Gentry, S. J.; Jones, A.; McNicol, B. D. Catal. Rev Sci. Eng. 1982, 24 (2), 233.

(21) Holm, V. C. F.; Clark, A. J. Catal. 1968, 11, 305.

(22) Finch, J. N. J. Catal. 1976, 43, 111.

(23) Davidov, A. A. in Infrared Spectroscopy of Adsorbed Species on the Surface of Transition Metal Oxides; Rochester, C. H., Ed.; John Wiley \& Sons: New York, 1984.

(24) More, J. W.; Pearson, R. G. In Kinetics and Mechanism, 3rd ed.; Wiley: New York, 1981.

(25) Bluestone, S.; Yan, K. Y. J. Chem. Educ. 1995, 72 (10), 884.

(26) Kung, H. H. Stud. Surf. Sci. Catal. 1989, 45, 91. 